Received: 14 February 2018

Accepted: 14 June 2018

Published online: 17 July 2018

CIENTIFIC REP

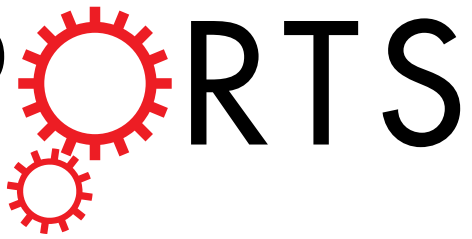

\title{
Socioeconomic determinants of
}

\section{sarcopenic obesity and frail obesity in community-dwelling older adults: The Seniors-ENRICA Study}

Belén Moreno-Franco ${ }^{1}$, Raúl F. Pérez-Tasigchana ${ }^{2,3}$, Esther Lopez-Garcia ${ }^{2,4}$, Martin Laclaustra ${ }^{1}$, Juan L. Gutierrez-Fisac ${ }^{2}$, Fernando Rodríguez-Artalejo ${ }^{2,4}$ \& Pilar Guallar-Castillón ${ }^{2,4}$

Information on the association between socioeconomic status (SES) throughout life and sarcopenic obesity is scarce, whereas no study has been focused on the association between SES and frail obesity. This analysis estimated the prevalence of sarcopenic obesity and frail obesity, and their associations with SES in older adults. Data were collected in 2012 from 1,765 non-institutionalized individuals aged $\geq 65$ participating in the Seniors-ENRICA study in Spain, by using standardized techniques and equipment. SES throughout life was evaluated with the father's occupation, participant's educational level, former own occupation, and current poor housing condition. Overall, $17.2 \%$ of participants had sarcopenic obesity, and $4.0 \%$ frail obesity. No association was found between SES and sarcopenic obesity. In contrast, the prevalence of frail obesity was higher in those with lower education, having worked in manual job, and currently having poor housing condition. Having $\geq 1$ social disadvantages throughout life was associated with higher prevalence of frail obesity. The prevalence of this disorder increased by $1.49(95 \% \mathrm{Cl}$ : 1.21-1.85) times for each social disadvantage added. The OR $(95 \% \mathrm{Cl})$ of frail obesity was 3.13 (1.71-5.7) for those having 3 or 4 vs. 0 or 1 social disadvantages, implying a more complex process beginning early in life.

The aging process is associated with loss of skeletal muscle mass (SMM) and strength, a phenomenon known as sarcopenia, which in turn is linked to higher risk of functional impairment and death ${ }^{1}$. Frailty is a geriatric syndrome characterized by loss of physiological and functional reserve that increases the vulnerability to even minor stressors (e.g.: dehydration, a cold, diarrhea, etc. $)^{2}$. As a result, frailty is associated with greater risk of falls, hospitalization, disability, and death ${ }^{3}$. Sarcopenia can be in the pathophysiological pathway to frailty, but they are independent syndromes.

Simultaneously with the process of sarcopenia that occurs in the elderly, there is an increase in fat mass, that is reflected in the high prevalence of obesity in recent decades worldwide ${ }^{4}$. Obesity induces a pro-inflammatory state through the release of adipokines such as IL- 6 and TNF- $\alpha$ which can increase muscle loss, and also modify muscle composition and quality, potentially affecting its functionality ${ }^{5-7}$. Thus, despite a low body mass index (BMI) it is still a predictor of sarcopenia ${ }^{8}$, also excess of adiposity couples with sarcopenia, characterizing the so called "sarcopenic obesity". It has been postulated that the synergistic association between sarcopenia and obesity may potentiate the effects of both syndromes separately, playing a probable role in the increased risk of cardiovascular disease and even of mortality. Nevertheless the results are still contradictory and dependent on the heterogeneity of the definitions of these syndromes ${ }^{9,10}$. In addition, although frailty is considered a wasting disorder, it can coexist with obesity as "frail obesity". In fact, so far today, longitudinal studies have only considered obesity as a determinant of frailty ${ }^{7,11,12}$, without considering frail obesity as a proper entity. Previously reported prevalence of sarcopenia and sarcopenic obesity in the Spanish population ranged between 13.8 and 24.1\%, and

${ }^{1}$ Translational Research Unit, Hospital Universitario Miguel Servet, Instituto de Investigación Sanitaria Aragón (IIS Aragón), Universidad de Zaragoza, CIBERCV, Zaragoza, Spain. ${ }^{2}$ Department of Preventive Medicine and Public Health, School of Medicine, Universidad Autónoma de Madrid/IdiPaz, CIBERESP, Madrid, Spain. ${ }^{3}$ School of Medicine, Universidad San Francisco de Quito, Quito, Ecuador. ${ }^{4}$ IMDEA-Food Institute, CEI UAM+CSIC, Madrid, Spain. Correspondence and requests for materials should be addressed to B.M.-F. (email: mbmoreno@unizar.es) 
11.0 and $14.9 \%$ respectively ${ }^{13,14}$. In addition, prevalence of frailty found in Spanish studies spans from 8.4 to 16.9, which makes it a potential problem for the aging Spanish demographics ${ }^{15-17}$.

Inequalities in socioeconomic status (SES) throughout life are associated with increased risk of morbidity and mortality ${ }^{18-22}$, and can lead to poor health outcomes later in life. It is well known that SES influences obesity ${ }^{23}$. Likewise, its relationship with sarcopenia and frailty has previously been studied ${ }^{24,25}$. However, information on the association between SES throughout life and sarcopenic obesity is scarce ${ }^{26}$, whereas no study has been focused on the association between SES and frail obesity. So, this study assessed the prevalence of sarcopenic and frail obesity, and its association with SES throughout life, in community-dwelling older adults.

\section{Methods}

Study design and participants. We used cross-sectional data from the second wave of the SeniorsENRICA cohort ${ }^{7,27}$. Briefly, this cohort was set up in 2008-2010 with 3,289 individuals, representative of the non-institutionalized Spanish population aged $\geq 60^{27}$. Participants were followed up to 2012 , when a second wave of data collection was performed. Data in this second wave were collected during a telephone interview on socio-demographic variables, lifestyle and morbidity. There were two subsequent home visits to obtain blood and urine samples, perform a physical examination, record habitual diet, and prescribed medication. After excluding 95 participants who died, 2,519 individuals provided updated information; of them, we excluded 264 participants aged $<65$, and 490 with missing data on anthropometry, impedanciometry, or SES components. Thus, the analyses were conducted with 1,765 subjects.

The Seniors-ENRICA study was approved by the Clinical Research Ethics Committee of La Paz University Hospital. All research was performed in accordance with relevant guidelines, and study participants gave informed written consent.

Study variables. Weight, height and percentage of body fat (\%BF) were measured in all participants. Height was measured twice with a portable extendable stadiometers (model Ka We $44444 \mathrm{Seca}$ ). Weight and \%BF was estimated by bioelectrical impedance analysis (BIA) (Tanita ${ }^{\circledR}$ SC-240MA, Tanita Corp., Tokyo, Japan). BMI was calculated as weight in $\mathrm{kg}$ divided by height in meters squared.

SMM $(\mathrm{kg})$ was calculated with the equation developed by Janssen et al. $.^{28}:\left(\left[\right.\right.$ Height ${ }^{2} /$ Resistance -0.401$]+[\mathrm{sex} \times$ $3.825]+$ [age $\times-0.071])+5.102$, where height is given in $\mathrm{cm}$, resistance in ohms (from BIA), sex as 1 for men and 0 for women, and age in years. Skeletal muscle mass index (SMI) was estimated by dividing SMM by height in meters squared. Sex-specific quintiles of SMI were created: $\leq 9.21 ; 9.22-10.06 ; 10.07-10.75 ; 10.76-11.67 ; \geq 11.69$ for men, and $\leq 7.07 ; 7.08-7.70 ; 7.71-8.31 ; 8.32-9.18$; $\geq 9.19$ for women. Sarcopenia was defined as the lower two quintiles of $\mathrm{SMI}^{29}$. Sex-specific quintiles of $\% \mathrm{BF}$ were: $\leq 22.30 ; 22.40-25.40 ; 25.44-28.70 ; 28.80-32.60 ; \geq 32.68$ for men, and $\leq 31.80 ; 31.82-35.70 ; 35.80-39.10 ; 39.20-42.60 ; \geq 42.70$ for women. Participants were classified as obese, when they were in the upper two quintiles of $\% \mathrm{BF}$.

Frailty was defined as having at least three of the five Fried's criteria ${ }^{30}$ : (1) exhaustion: any of the following responses to two questions taken from the Center for Epidemiologic Studies Depression Scale ${ }^{31}$ : "I feel that anything I do is a big effort" or "I feel that I cannot keep on doing things" at least 3-4 days a week; (2) weight loss: unintentional loss of $\geq 4.5 \mathrm{~kg}$ of body weight in the preceding year; (3) low physical activity: walking $\leq 2.5 \mathrm{~h} /$ week in men or $\leq 2 \mathrm{~h} /$ week in women ${ }^{31}$; (4) weakness: the cohort-specific lowest quintile of grip strength adjusted for sex and $\mathrm{BMI}^{32}$. Strength was measured with a Jamar dynamometer, previously calibrated, and the highest value in two consecutive measurements was used in the analyses; and (5) slow walking speed: the lowest cohort-specific quintile in the three-meter walking speed test, adjusted for sex and height ${ }^{33}$.

Based on the aforesaid cross-tabulated bounds of \%BF and SMI, sarcopenic obesity was diagnosed when participants were in the upper two quintiles of $\% \mathrm{BF}$ and in the lower two quintiles of $\mathrm{SMI}^{29}$. Likewise, frail obesity was diagnosed when participants were in the upper two quintiles of $\% \mathrm{BF}$ and met $\geq 3$ Fried criteria.

Socioeconomic status. Father's occupation, educational level, former own occupation (almost all participants were currently retired), and current housing conditions were considered as proxies for SES, corresponding respectively to their SES in different periods in life: childhood, youth, adulthood, and late life. Father's occupation and formal own occupation (corresponding to the current or last job held) were classified according to the National Classification of Occupations in Spain, and grouped into manual and non-manual jobs. Housewives were assigned the occupation of their husbands. Educational level was assessed as the highest level reached (primary or lower, secondary, and university). Individuals were identified as having housing disadvantage when they lived in a house with at least one of the following poor conditions: no elevator in a walk-up building, feeling cold often, or having no heating. Having housing disadvantage was considered as a proxy for current low SES. Having at least one social disadvantage throughout life was considered when they met at least one of the following conditions: father's manual occupation, primary studies or lower, former own manual occupation, and living in poor housing conditions. A scale was constructed to assess the accumulation of social disadvantages throughout life by adding one point for each previous criteria (range 0-4).

Other variables. Apart from sex and age, the interview collected participant's own-reported physiciandiagnosed diseases: cardiovascular diseases (heart attack, stroke, heart failure or atrial fibrillation), asthma or chronic bronchitis, osteoarticular diseases (osteoarthritis, rheumatoid arthritis or hip fracture), cancer at any site, and depression requiring drug treatment. Individuals also reported self-rated health and their health-related quality of life (HRQL) using the SF-12 questionnaire from which mental and physical scores were calculated.

Statistical analysis. The prevalence of sarcopenic and frail obesity was calculated and the chi-square test was used to assess age- and sex-differences. Mean and standard deviation (SD) were used to describe characteristics of the participants in the study according to SES components. We used logistic regression to assess the 


\begin{tabular}{|l|l|l|l|l|l|l|}
\hline \multirow{2}{*}{} & \multicolumn{3}{|l|}{ Sarcopenic obesity } & \multicolumn{3}{l|}{ Frail obesity } \\
\cline { 2 - 7 } & $\mathbf{N}$ & $\mathbf{n}$ & $\%$ & $\mathbf{N}$ & $\mathbf{n}$ & $\%$ \\
\hline Overall & 1730 & 298 & 17.2 & 1764 & 71 & 4.0 \\
\hline$<75$ & 1144 & 199 & 17.4 & 1168 & 30 & 2.6 \\
\hline$\geq 75$ & 586 & 99 & 16.9 & 596 & 41 & $6.9^{\mathrm{a}}$ \\
\hline Men & 808 & 147 & 18.2 & 829 & 12 & 1.4 \\
\hline$<75$ & 549 & 100 & 18.2 & 565 & 5 & 0.9 \\
\hline$\geq 75$ & 259 & 47 & 18.1 & 264 & 7 & $2.6^{\mathrm{a}}$ \\
\hline Women & 922 & 151 & 16.4 & 935 & 59 & $6.3^{\mathrm{b}}$ \\
\hline$<75$ & 595 & 99 & 16.6 & 603 & 25 & 4.1 \\
\hline$\geq 75$ & 327 & 52 & 15.9 & 332 & 34 & $10.2^{\mathrm{a}}$ \\
\hline
\end{tabular}

Table 1. Frequency of sarcopenic and frail obesity by sex and age, Seniors-ENRICA cohort (2012). Notes: Statistically significant between groups $(\mathrm{p}<0.05) \mathrm{:}^{\mathrm{a}}<75 \mathrm{vs}$. $\geq 75$; ${ }^{\mathrm{b}} \mathrm{Men}$ vs. Women.

association of each social disadvantage throughout life with sarcopenic and frail obesity. Regression models were adjusted for age and sex. We used the SES throughout life as a continuous variable to assess the association between the increase in one social disadvantage and sarcopenic obesity or frail obesity. In addition, this scale was divided into three categories ( 0 or 1, 2, 3 or 4 disadvantages), being 0 or 1 the reference category. A p for linear trend was calculated by modelling the independent variable as continuous. Results are presented as odds ratios (OR) and their $95 \%$ confidence interval (CI). We conducted sensitivity analyses with a modified definition of sarcopenic obesity and frail obesity, by considering obesity as BMI $\geq 30 \mathrm{~kg} / \mathrm{m}^{2}$. Analyses were performed with IBM SPSS for Windows, version 22.0 (Armonk, NY; IBM Corp.), and $\mathrm{p}<0.05$ was considered statistically significant.

Data availability. The datasets generated during and/or analyzed during the current study are available from the corresponding author on reasonable request.

\section{Results}

The sample consisted of 1,765 participants, 830 men and 935 women, ranging from 65 to 97 years old. From the total sample, $17.2 \%$ (95\% CI: 15.4-19.0) had sarcopenic obesity. No differences were found in the prevalence of this condition between men and women, or age groups (Table 1). Sensitivity analysis showed that when BMI criterion was used $\left(\geq 30 \mathrm{~kg} / \mathrm{m}^{2}\right)$ instead of $\% \mathrm{BF}$ to be considered obese, the prevalence for sarcopenic obesity was $5.9 \%$ (95\% CI: 4.7-7.0). A total of $4.0 \%$ (95\% CI: 3.1-4.9) of participants had frail obesity. The frequency was higher in women and those aged 75 years-old or above (Table 1). Sensitivity analysis showed that when obesity was defined as BMI $\geq 30 \mathrm{~kg} / \mathrm{m}^{2}$, the prevalence of frail obesity was similar, $4.1 \%$ (95\% CI: 3.2-5.0). Both conditions partially overlapped. Among those with sarcopenic obesity, $8.7 \%$ were also obese frail. Among obese frail, $36.6 \%$ were also obese sarcopenic.

From the total sample, $32.2 \%$ (95\% CI: 30.0-34.4) had a father with manual occupation, $45.5 \%$ (95\% CI: 43.2-47.8) had primary or lower educational level, 38.1\% (95\% CI: 35.9-40.4) had former own manual occupation, and 35.9\% (95\% CI: 33.6-38.1) had at least one poor housing condition. We noticed a higher frequency of women in all these groups $(53.8 \%, 61.9 \%, 56.2 \%$ and $57.8 \%$ respectively). Those in the lowest socioeconomic groups were observed to have worse auto-perceived health, lower HRQL, and greater morbidity. There was a large difference in the frequency of osteoarticular diseases between those with primary or university studies $(56.7 \%$ vs. $36.0 \%$ ), and between those with and without housing disadvantage ( $54.7 \%$ vs. $45.6 \%)$. Likewise, depression was more frequently reported by those with primary education compared with those with university studies (12.4\% vs. $1.5 \%)$. No differences were found in the prevalence of sarcopenic obesity across SES categories. However, the prevalence of frail obesity was higher in all the lowest socioeconomic groups. The most pronounced differences occurred between those with primary and university education (5.9 vs. 1.5) (Table 2).

Once adjusted for age and sex, none of SES variables were associated with sarcopenic obesity. On the contrary, frail obesity was associated with older age (OR 2.71, 95\% CI: 1.67-4.40), being a woman (OR 4.49, 95\% CI: 2.39-8.44), lower education (OR 2.66, 95\% CI: 1.12-6.32), former own manual occupation (OR 1.83, 95\% CI: 1.13-2.98), and having at least one poor housing condition (OR 1.77, 95\% CI: 1.09-2.88). Having at least one social disadvantage throughout life also increased the prevalence of having frail obesity (OR 3.45, 95\% CI: 1.24-9.61). The likelihood of suffering from frail obesity was increased by 1.49 (95\% CI: 1.21-1.85) times for each social disadvantage added (Table 3). Likewise, having 3 or 4 social disadvantages obtained an OR of 3.13 (95\% CI: 1.71-5.70) when comparing to 0 or 1 disadvantages (Table 4 ).

\section{Discussion}

This cross-sectional analysis conducted with a population-based study in Spain, showed a prevalence of sarcopenic obesity of $17.2 \%$, and a prevalence of frail obesity of $4.0 \%$. No association was found between SES and sarcopenic obesity. In contrast, lower educational level, having worked in manual jobs, and having poor housing conditions were associated with frail obesity. In addition, having at least one social disadvantage throughout life substantially increased the prevalence of having frail obesity.

Few studies have determined the prevalence of sarcopenic obesity in Spain, reporting a slightly lower frequency (14.9\% vs. $17.2 \%$ ), also using sex specific quintiles of $\% \mathrm{BF}$ and $\mathrm{SMI}^{14}$. In Europe, a study performed between 2011 and 2012 showed, by means of predictive equations, that $11.0 \%$ of the 1,865 Spanish participants 


\begin{tabular}{|c|c|c|c|c|c|c|c|c|c|}
\hline & \multicolumn{2}{|c|}{ Father's occupation } & \multicolumn{3}{|c|}{ Educational level } & \multicolumn{2}{|c|}{ Former own occupation } & \multicolumn{2}{|c|}{ Poor housing condition } \\
\hline & $\begin{array}{l}\text { Non-manual } \\
\mathrm{N}=1196\end{array}$ & $\begin{array}{l}\text { Manual } \\
\mathrm{N}=569\end{array}$ & $\begin{array}{l}\text { University } \\
\mathrm{N}=389\end{array}$ & $\begin{array}{l}\text { Secondary } \\
\mathrm{N}=414\end{array}$ & $\begin{array}{l}\leq \text { Primary } \\
\mathbf{N}=962\end{array}$ & $\begin{array}{l}\text { Non-manual } \\
\mathrm{N}=1092\end{array}$ & $\begin{array}{l}\text { Manual } \\
N=673\end{array}$ & No $N=1132$ & Yes $N=633$ \\
\hline \multicolumn{10}{|l|}{ Sociodemographic } \\
\hline Age (years) & $72.9(5.8)$ & $72.3(6.0)$ & $71.9(5.6)$ & $71.5(5.8)$ & $73.6(5.9)$ & $72.7(6.0)$ & $72.8(5.8)$ & $72.8(6.0)$ & $72.6(5.8)$ \\
\hline Women (\%) & 52.6 & 53.8 & 38.8 & 45.7 & 61.9 & 51.0 & 56.2 & 50.3 & 57.8 \\
\hline \multicolumn{10}{|l|}{ Morbidity } \\
\hline \multicolumn{10}{|l|}{ Self-perceived health (\%) } \\
\hline Excellent/Very good/Good & 66.9 & 60.3 & 81.9 & 75.5 & 53.0 & 68.6 & 58.5 & 66.8 & 61.1 \\
\hline Regular/Bad & 33.1 & 39.7 & 18.1 & 24.5 & 47.0 & 31.4 & 41.5 & 33.2 & 38.9 \\
\hline Physical health score (SF-12) & $45.2(12.0)$ & $43.6(12.4)$ & $48.0(10.8)$ & $46.7(11.2)$ & $42.5(12.7)$ & $45.6(11.8)$ & $43.3(12.7)$ & $44.9(12.0)$ & $44.4(12.6)$ \\
\hline Mental health score (SF-12) & $53.2(10.6)$ & $52.8(11.1)$ & $55.2(8.4)$ & $54.2(9.0)$ & $51.7(12.1)$ & $53.5(10.4)$ & $52.4(11.4)$ & $53.8(10.4)$ & $51.8(11.3)$ \\
\hline Cardiovascular disease (\%) ${ }^{\mathrm{a}}$ & 6.4 & 8.3 & 7.0 & 7.8 & 6.7 & 6.8 & 7.3 & 7.2 & 6.7 \\
\hline Asthma or chronic bronchitis (\%) & 11.5 & 12.7 & 9.8 & 10.0 & 13.5 & 11.9 & 11.8 & 11.1 & 13.3 \\
\hline Osteoarticular diseases $(\%)^{\mathrm{b}}$ & 48.3 & 50.1 & 36.0 & 43.2 & 56.7 & 46.5 & 52.7 & 45.6 & 54.7 \\
\hline Cancer (\%) & 3.1 & 3.5 & 3.6 & 2.7 & 3.3 & 2.9 & 3.7 & 2.6 & 4.4 \\
\hline Depression (\%) & 8.4 & 9.7 & 1.5 & 7.5 & 12.4 & 7.3 & 11.3 & 8.0 & 10.3 \\
\hline Sarcopenic obesity (\%) & 17.0 & 17.1 & 19.1 & 15.6 & 16.8 & 17.2 & 16.8 & 18.0 & 15.2 \\
\hline Frail obesity (\%) & 3.6 & 4.9 & 1.5 & 1.9 & 5.9 & 3.0 & 5.6 & 3.1 & 5.7 \\
\hline
\end{tabular}

Table 2. Sociodemographic and morbidity characteristics of study participants by socioeconomic status components, Seniors-ENRICA cohort (2012). Continuous variables are expressed as mean \pm SD. ${ }^{\text {SSelf-reported }}$ heart attack, stroke, heart failure or atrial fibrillation. 'belf-reported osteoarthritis, rheumatoid arthritis or hip fracture.

aged $\geq 65$ had sarcopenic obesity ${ }^{13}$. In France, a lower prevalence was also found from the analysis of 1,308 institutionalized healthy women aged $\geq 75$. Of them, $2.8 \%$ were identified as obese sarcopenic ${ }^{34}$. In the US, a cross-sectional analysis performed with 2,287 subjects aged 60 and older from the National Health and Nutrition Examination Survey (NHANES 1999-2004) reported that 10.4\% were obese sarcopenic. In this case, waist circumference was used to assess obesity, and appendicular SMM was measured by dual-energy X-ray absorptiometry (DXA) ${ }^{35}$. Finally, data from the Nutrition as a Determinant of Successful Aging (NuAge) Study in Canada, with 904 community-dwelling individuals aged between 68 and 82 showed a prevalence of $18.8 \%$ in men, and $10.8 \%$ in women (the European Working Group on Sarcopenic in Older People criteria were used for sarcopenia diagnosis, and body composition was assessed by DXA $)^{36}$.

Marked differences exist in the prevalence among studies. Comparison of results on sarcopenic obesity is still somewhat complex due to the heterogeneity of the methods and cut-off points used to assess both SMM and obesity. Since first defined sarcopenia in 1998 by Baumgartner et al. as appendicular SMM $\left(\mathrm{kg} / \mathrm{m}^{2}\right)$ less than two standard deviations below the sex-specific mean in a young reference group ${ }^{37}$, several definitions have been proposed relying on muscle mass, but also on strength and physical performance ${ }^{38}$. Coupled with this problem, the lack of consensus in determining high fat mass makes sarcopenic obesity prevalence vary widely ${ }^{39}$. In fact, in our analysis it ranged from $17.2 \%$ using $\%$ BF to $5.8 \%$ using BMI as diagnostic criteria. However, prevalence of frail obesity was similar when using BMI $\geq 30 \mathrm{~kg} / \mathrm{m} 2$. The use of BMI as an indicator of obesity in the elderly has been questioned due to changes in body composition with ageing, since it does not take into account the loss of muscle mass ${ }^{40}$. On the other hand, the utilization of computed tomography and magnetic resonance (considered as the gold standard methods in research), is of limited use in epidemiological studies due to the emission of radiation and high cost, being DXA and BIA (considered to be a portable alternative to DXA) the most common instruments to assess sarcopenic obesity in general populations.

Influence of SES on health has been widely reported. It is known that, social inequalities begin in childhood, and can be sustained throughout life, but the way they impact negatively on some health events later in life remains unclear. Educational level, as a SES indicator in youth, constitutes a strong predictor of future type of employment, and it is considered the socioeconomic factor with most influence on health. Thus, educational inequalities have been related with a worse HRQL in the elderly ${ }^{41}$. Likewise, studies conducted both in Europe and USA, have reported an increased risk of mortality in those with lower educational level ${ }^{21,22}$. Among middle age participants, manual work could involve greater exposure to certain conditions, which may influence physical and mental health in the elderly ${ }^{18,19}$, as well as in achieving a better HRQL after labour market ${ }^{42}$. Midlife adversities like low occupational position or high job strain have been associated with post-retirement depressive symptoms ${ }^{18}$. Besides, higher midlife occupational physical activity levels, have been related to major risk of disability later in life ${ }^{19}$. Finally, it is probable that all previously mentioned factors could influence people to have less access to a better equipped house later in life. There are grounds for believing that older adults are probably more exposed to certain social disadvantage like lower purchasing power. It is also known that, retired people are at greater risk of physical disability and frailty ${ }^{43}$, and those conditions increase in those with fewer resources ${ }^{20}$.

Some information on SES and its relationship with sarcopenia and frailty is available ${ }^{24,25}$. Though, data studying this association with sarcopenic obesity is scarce ${ }^{26}$, whereas no study has evaluated its link with frail obesity. Moreover, SES throughout life has never been assessed. We observed no association between sarcopenic obesity 


\begin{tabular}{|c|c|c|c|c|c|c|}
\hline & \multirow[b]{2}{*}{$\mathbf{N}$} & \multicolumn{2}{|c|}{ Sarcopenic obesity } & \multirow[b]{2}{*}{$\mathbf{N}$} & \multicolumn{2}{|c|}{ Frail obesity } \\
\hline & & $\mathbf{n}$ & OR $(95 \% \mathrm{CI})^{\mathrm{a}}$ & & $\mathbf{n}$ & OR $(95 \% \mathrm{CI})^{\mathrm{a}}$ \\
\hline \multicolumn{7}{|l|}{ Age } \\
\hline$<75$ & 1144 & 199 & Ref. & 1168 & 30 & Ref. \\
\hline$\geq 75$ & 586 & 99 & $0.97(0.74-1.26)$ & 596 & 41 & $2.71(1.67-4.40)$ \\
\hline \multicolumn{7}{|l|}{ Sex } \\
\hline Men & 808 & 147 & Ref. & 829 & 12 & Ref. \\
\hline Women & 922 & 151 & $0.88(0.67-1.14)$ & 935 & 59 & $4.49(2.39-8.44)$ \\
\hline \multicolumn{7}{|l|}{ Father's occupation } \\
\hline Non-manual & 1168 & 201 & Ref. & 1195 & 43 & Ref. \\
\hline Manual & 562 & 97 & $1.00(0.77-1.31)$ & 569 & 28 & $1.38(0.84-2.26)$ \\
\hline \multicolumn{7}{|l|}{ Educational level } \\
\hline University & 382 & 74 & Ref. & 389 & 6 & Ref. \\
\hline Secondary & 406 & 64 & $0.78(0.54-1.13)$ & 414 & 8 & $1.17(0.40-3.43)$ \\
\hline$\leq$ Primary & 942 & 160 & $0.89(0.65-1.21)$ & 961 & 57 & $2.66(1.12-6.32)$ \\
\hline \multicolumn{7}{|l|}{ Former own occupation } \\
\hline Non-manual & 1072 & 186 & Ref. & 1091 & 33 & Ref. \\
\hline Manual & 658 & 112 & $0.98(0.76-1.27)$ & 673 & 38 & $1.83(1.13-2.98)$ \\
\hline \multicolumn{7}{|l|}{ At least one poor housing condition } \\
\hline No & 1110 & 203 & Ref. & 1131 & 35 & Ref. \\
\hline Yes & 620 & 95 & $0.81(0.62-1.06)$ & 633 & 36 & $1.77(1.09-2.88)$ \\
\hline \multicolumn{7}{|c|}{ At least one social disadvantage throughout life } \\
\hline No & 352 & 63 & Ref. & 358 & 4 & Ref. \\
\hline Yes & 1378 & 235 & $0.96(0.71-1.31)$ & 1406 & 67 & $3.45(1.24-9.61)$ \\
\hline The increase of one social disadvantage & 1730 & - & $0.96(0.87-1.07)$ & 1764 & - & $1.49(1.21-1.85)$ \\
\hline
\end{tabular}

Table 3. Association between presenting sarcopenic obesity or frail obesity and sociodemographic characteristics and socioeconomic status, Seniors-ENRICA cohort (2012). ${ }^{\mathrm{a}}$ Model adjusted for age (as a continuous variable) and sex (except for the stratification variable).

\begin{tabular}{|l|l|l|l|c|}
\hline \multirow{2}{*}{} & \multicolumn{4}{|l}{ Number of social disadvantages throughout life } \\
\cline { 2 - 5 } & $\mathbf{0 / 1}$ & $\mathbf{2}$ & $\mathbf{3 / 4}$ & p-trend \\
\hline Sarcopenic obesity & $153 / 850$ & $72 / 458$ & $73 / 422$ & \\
\hline OR $(95 \% \text { CI })^{\mathrm{a}}$ & Ref. & $0.86(0.63-1.17)$ & $0.97(0.71-1.32)$ & 0.726 \\
\hline Frail obesity & $18 / 868$ & $21 / 465$ & $32 / 431$ & \\
\hline OR $(95 \%$ CI) & Ref. & $1.89(0.98-3.61)$ & $3.13(1.71-5.70)$ & $<0.001$ \\
\hline
\end{tabular}

Table 4. Association between the number of social disadvantages throughout life and the probability of suffering from sarcopenic obesity or frail obesity, Seniors-ENRICA cohort (2012). Notes: OR= Odds ratio; $\mathrm{IC}=$ Confidence interval. ${ }^{\mathrm{a}}$ Model adjusted for age (as a continuous variable) and sex.

and any of the SES variables. These data are in line with those reported by Tyrovolas et al. who found similar results when assessing SES as educational level and wealth ${ }^{26}$. Our results showed an association between being in social disadvantage and suffering from frail obesity. Interestingly, all the SES determinants were positively and statistically associated with frail obesity, except father's occupation, that also is the furthest in the causal pathway. Moreover, those with at least one social disadvantage throughout life presented a probability up to threefold higher risk of being obese frail than those without any social disadvantage.

We observed that sarcopenic obesity appears more frequently among those with higher levels of education, while frail obesity does among those with just primary studies. It is likely that more educated subjects may have lower muscle mass, probably because they have more sedentary jobs. However, it is plausible that their SES allowed them to access better health services, and associates better nutritional habits and self-care which may have avoided the frailty characteristic loss of function. This reason justifies that education, as a determinant of health, should be part of an integral form in the new approach to public health.

To the best of our knowledge, this is the first study to evaluate the association between frail obesity and SES determinants in community-dwelling older adults. It has the strength of having been carried out by means of standardized protocols. Additionally, a basic adjustment was performed. However, it has also several limitations. The main one is the cross-sectional nature of the data that may suffer from survival, recall, and selection biases. Owing to the difficulty obtaining self-reported information on income among the elderly, we did not consider this variable, even though, the best way to measure SES is probably combining education, occupation, and income. In addition, a small number of cases in some stratified groups were found, especially for frailty. Also, the use of specific quintiles in our sample to define the events makes it difficult to generalize our results, due to the lack of normative cut-off points. 


\section{Conclusions}

This study emphasizes the need for consensual criteria in the diagnosis of these syndromes, and to point out the need for an agreement on the definitions, cut-off points, and measurement methods, in order to be used in general populations of older adults. At the same time, this research highlights the special importance of education and SES throughout life in the prevalence of frailty related to obesity, but not for sarcopenic obesity. This probably implies that for frail obesity, determinants could have been operating for a long period of time, implying a complex process beginning early in life.

\section{References}

1. Cruz-Jentoft, A. J. et al. Sarcopenia: European consensus on definition and diagnosis: Report of the European Working Group on Sarcopenia in Older People. Age Ageing 39, 412-423, https://doi.org/10.1093/ageing/afq034 (2010).

2. Rockwood, K. Frailty and its definition: a worthy challenge. J Am Geriatr Soc 53, 1069-1070, https://doi.org/10.1111/j.15325415.2005.53312.x (2005).

3. Clegg, A., Young, J., Iliffe, S., Rikkert, M. O. \& Rockwood, K. Frailty in elderly people. Lancet 381, 752-762, https://doi.org/10.1016/ S0140-6736(12)62167-9 (2013).

4. Mathus-Vliegen, E. M. Obesity and the elderly. J Clin Gastroenterol 46, 533-544, https://doi.org/10.1097/MCG.0b013e31825692ce (2012).

5. Lee, C. G. et al. Association between insulin resistance and lean mass loss and fat mass gain in older men without diabetes mellitus. J Am Geriatr Soc 59, 1217-1224, https://doi.org/10.1111/j.1532-5415.2011.03472.x (2011).

6. Park, S. W. et al. Accelerated loss of skeletal muscle strength in older adults with type 2 diabetes: the health, aging, and body composition study. Diabetes Care 30, 1507-1512, https://doi.org/10.2337/dc06-2537 (2007).

7. Garcia-Esquinas, E. et al. Obesity, fat distribution, and risk of frailty in two population-based cohorts of older adults in Spain. Obesity (Silver Spring) 23, 847-855, https://doi.org/10.1002/oby.21013 (2015).

8. Goodman, M. J. et al. Development of a practical screening tool to predict low muscle mass using NHANES 1999-2004. J Cachexia Sarcopenia Muscle 4, 187-197, https://doi.org/10.1007/s13539-013-0107-9 (2013).

9. Stephen, W. C. \& Janssen, I. Sarcopenic-obesity and cardiovascular disease risk in the elderly. J Nutr Health Aging 13, 460-466 (2009).

10. Atkins, J. L. et al. Sarcopenic obesity and risk of cardiovascular disease and mortality: a population-based cohort study of older men. J Am Geriatr Soc 62, 253-260, https://doi.org/10.1111/jgs.12652 (2014).

11. Trevisan, C. et al. Factors Influencing Transitions Between Frailty States in Elderly Adults: The Progetto Veneto Anziani Longitudinal Study. J Am Geriatr Soc 65, 179-184, https://doi.org/10.1111/jgs.14515 (2017).

12. Ottenbacher, K. J. et al. Frailty in older Mexican Americans. J Am Geriatr Soc 53, 1524-1531, https://doi.org/10.1111/j.15325415.2005.53511.x (2005).

13. Tyrovolas, S. et al. The role of muscle mass and body fat on disability among older adults: A cross-national analysis. Exp Gerontol 69, 27-35, https://doi.org/10.1016/j.exger.2015.06.002 (2015).

14. Gomez-Cabello, A. et al. Prevalence of overweight and obesity in non-institutionalized people aged 65 or over from Spain: the elderly EXERNET multi-centre study. Obes Rev 12, 583-592, https://doi.org/10.1111/j.1467-789X.2011.00878.x (2011).

15. Garcia-Garcia, F. J. et al. The prevalence of frailty syndrome in an older population from Spain. The Toledo Study for Healthy Aging. J Nutr Health Aging 15, 852-856 (2011).

16. Alcala, M. V. et al. Prevalence of frailty in an elderly Spanish urban population. Relationship with comorbidity and disability. Aten Primaria 42, 520-527, https://doi.org/10.1016/j.aprim.2009.09.024 (2010).

17. Abizanda, P. et al. Prevalence of frailty in a Spanish elderly population: the Frailty and Dependence in Albacete study. J Am Geriatr Soc 59, 1356-1359, https://doi.org/10.1111/j.1532-5415.2011.03463.x (2011).

18. Virtanen, M. et al. Socioeconomic and psychosocial adversity in midlife and depressive symptoms post retirement: a 21 -year followup of the Whitehall II study. Am J Geriatr Psychiatry 23, 99-109 e101, https://doi.org/10.1016/j.jagp.2014.04.001 (2015).

19. Missikpode, C., Michael, Y. L. \& Wallace, R. B. Midlife Occupational Physical Activity and Risk of Disability Later in Life: National Health and Aging Trends Study. J Am Geriatr Soc 64, 1120-1127, https://doi.org/10.1111/jgs.14083 (2016).

20. Wahrendorf, M., Reinhardt, J. D. \& Siegrist, J. Relationships of disability with age among adults aged 50 to 85 : evidence from the United States, England and continental europe. PLoS One 8, e71893, https://doi.org/10.1371/journal.pone.0071893 (2013).

21. Mackenbach, J. P. et al. Socioeconomic inequalities in health in 22 European countries. N Engl J Med 358, 2468-2481, https://doi. org/10.1056/NEJMsa0707519 (2008).

22. Galea, S., Tracy, M., Hoggatt, K. J., Dimaggio, C. \& Karpati, A. Estimated deaths attributable to social factors in the United States. Am J Public Health 101, 1456-1465, https://doi.org/10.2105/AJPH.2010.300086 (2011).

23. Dinsa, G. D., Goryakin, Y., Fumagalli, E. \& Suhrcke, M. Obesity and socioeconomic status in developing countries: a systematic review. Obes Rev 13, 1067-1079, https://doi.org/10.1111/j.1467-789X.2012.01017.x (2012).

24. Barbosa-Silva, T. G., Bielemann, R. M., Gonzalez, M. C. \& Menezes, A. M. Prevalence of sarcopenia among community-dwelling elderly of a medium-sized South American city: results of the COMO VAI? study. J Cachexia Sarcopenia Muscle 7, 136-143, https:// doi.org/10.1002/jcsm.12049 (2016).

25. Arrighi, Y., Rapp, T. \& Sirven, N. The impact of economic conditions on the disablement process: A Markov transition approach using SHARE data. Health Policy 121, 778-785, https://doi.org/10.1016/j.healthpol.2017.05.002 (2017).

26. Tyrovolas, S. et al. Factors associated with skeletal muscle mass, sarcopenia, and sarcopenic obesity in older adults: a multi-continent study. J Cachexia Sarcopenia Muscle 7, 312-321, https://doi.org/10.1002/jcsm.12076 (2016).

27. Rodriguez-Artalejo, F. et al. Rationale and methods of the study on nutrition and cardiovascular risk in Spain (ENRICA). Rev Esp Cardiol 64, 876-882, https://doi.org/10.1016/j.recesp.2011.05.019 (2011).

28. Janssen, I., Heymsfield, S. B., Baumgartner, R. N. \& Ross, R. Estimation of skeletal muscle mass by bioelectrical impedance analysis. J Appl Physiol (1985) 89, 465-471 (2000).

29. Davison, K. K., Ford, E. S., Cogswell, M. E. \& Dietz, W. H. Percentage of body fat and body mass index are associated with mobility limitations in people aged 70 and older from NHANES III. J Am Geriatr Soc 50, 1802-1809 (2002).

30. Fried, L. P. et al. Frailty in older adults: evidence for a phenotype. J Gerontol A Biol Sci Med Sci 56, M146-156 (2001).

31. Washburn, R. A., Smith, K. W., Jette, A. M. \& Janney, C. A. The Physical Activity Scale for the Elderly (PASE): development and evaluation. J Clin Epidemiol 46, 153-162 (1993).

32. Ottenbacher, K. J. et al. The reliability of upper- and lower-extremity strength testing in a community survey of older adults. Arch Phys Med Rehabil 83, 1423-1427 (2002).

33. Guralnik, J. M. et al. A short physical performance battery assessing lower extremity function: association with self-reported disability and prediction of mortality and nursing home admission. J Gerontol 49, M85-94 (1994).

34. Rolland, Y. et al. Difficulties with physical function associated with obesity, sarcopenia, and sarcopenic-obesity in communitydwelling elderly women: the EPIDOS (EPIDemiologie de l'OSteoporose) Study. Am J Clin Nutr 89, 1895-1900, https://doi. org/10.3945/ajcn.2008.26950 (2009). 
35. Levine, M. E. \& Crimmins, E. M. The impact of insulin resistance and inflammation on the association between sarcopenic obesity and physical functioning. Obesity (Silver Spring) 20, 2101-2106, https://doi.org/10.1038/oby.2012.20 (2012).

36. Bouchard, D. R., Dionne, I. J. \& Brochu, M. Sarcopenic/obesity and physical capacity in older men and women: data from the Nutrition as a Determinant of Successful Aging (NuAge)-the Quebec longitudinal Study. Obesity (Silver Spring) 17, 2082-2088, https://doi.org/10.1038/oby.2009.109 (2009).

37. Baumgartner, R. N. et al. Epidemiology of sarcopenia among the elderly in New Mexico. Am J Epidemiol 147, 755-763 (1998).

38. Dupuy, C. et al. Searching for a relevant definition of sarcopenia: results from the cross-sectional EPIDOS study. J Cachexia Sarcopenia Muscle 6, 144-154, https://doi.org/10.1002/jcsm.12021 (2015).

39. Batsis, J. A. et al. Variation in the prevalence of sarcopenia and sarcopenic obesity in older adults associated with different research definitions: dual-energy X-ray absorptiometry data from the National Health and Nutrition Examination Survey 1999-2004. J Am Geriatr Soc 61, 974-980, https://doi.org/10.1111/jgs.12260 (2013).

40. Wannamethee, S. G. \& Atkins, J. L. Muscle loss and obesity: the health implications of sarcopenia and sarcopenic obesity. Proc Nutr Soc 74, 405-412, https://doi.org/10.1017/S002966511500169X (2015).

41. Mangen, M. J. et al. Quality of life in community-dwelling Dutch elderly measured by EQ-5D-3L. Health Qual Life Outcomes 15, 3, https://doi.org/10.1186/s12955-016-0577-5 (2017).

42. Platts, L. G. et al. Physical occupational exposures during working life and quality of life after labour market exit: results from the GAZEL study. Aging Ment Health 17, 697-706, https://doi.org/10.1080/13607863.2013.781120 (2013).

43. Stenholm, S. et al. Age-related trajectories of physical functioning in work and retirement: the role of sociodemographic factors, lifestyle and disease. J Epidemiol Community Health 68, 503-509, https://doi.org/10.1136/jech-2013-203555 (2014).

\section{Acknowledgements}

Data collection was funded by the following grants: PI13/0288; PI14/0009; PI16/01460; PI16/01512; and PI16/00609 (State Secretary of R+D and FEDER/FSE). BM-F was supported by a CIBERCV contract, RFP-T was supported by the National Government of Ecuador through the National Institution of Higher Education, Science, Technology and Innovation-SENESCYT, and ML research activity is funded by Agencia Aragonesa para la Investigación y el Desarrollo (ARAID).

\section{Author Contributions}

B.M.-F. performed the statistical data analysis, interpreted the results, and wrote the manuscript. P.G.-C. and F.R.-A. conceptualized the research question and designed the study. R.F.P.-T., E.L.-G., M.L., J.L.G.-F., F.R.-A., P.G.-C., were involved with interpretation of data and revising the manuscript for important intellectual content. All authors approved the final version of the manuscript for publication.

\section{Additional Information}

Competing Interests: The authors declare no competing interests.

Publisher's note: Springer Nature remains neutral with regard to jurisdictional claims in published maps and institutional affiliations.

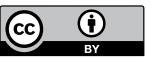

Open Access This article is licensed under a Creative Commons Attribution 4.0 International License, which permits use, sharing, adaptation, distribution and reproduction in any medium or format, as long as you give appropriate credit to the original author(s) and the source, provide a link to the Creative Commons license, and indicate if changes were made. The images or other third party material in this article are included in the article's Creative Commons license, unless indicated otherwise in a credit line to the material. If material is not included in the article's Creative Commons license and your intended use is not permitted by statutory regulation or exceeds the permitted use, you will need to obtain permission directly from the copyright holder. To view a copy of this license, visit http://creativecommons.org/licenses/by/4.0/.

(C) The Author(s) 2018 